\title{
The Comparison of Gabapentin and Amitriptilin Effectivity as Pain Therapy in Herniated Nucleus Pulposus
}

\author{
Indriastuti Cahyaningsih ${ }^{1}$, Rina Handayani ${ }^{2}$, Setyaningsih ${ }^{3}$ \\ ${ }^{1}$ Department of Pharmacology and Clinical Pharmacy, Faculty of Medicine and Health Sciences \\ Universitas Muhammadiyah Yogyakarta, Indonesia \\ ${ }^{2}$ Department of Pharmacology and Clinical Pharmacy, Faculty of Pharmacy, Universitas Gadjah Mada, Indonesia \\ ${ }^{3}$ Neurology Department Jogja Hospital, Indonesia
}

\begin{abstract}
Article Info
ABSTRACT

Article history:

Received Jul 23, 2015

Revised Aug 24, 2015

Accepted Aug 30, 2015

Keyword:

Amitriptilin

Effectivity

Herniated nucleus pulposus

Gabapentin

Herniated nucleus pulposus (HNP) is one of peripheral neuropathic pain. Although concensus guidelines for the treatment of neuropathic pain are based on the results of the RCT studies, there are still gaps in the literatures. This study aimed to compare the effectiveness and quality of life of gabapentin and amitriptyline for the treatment of pain in HNP. The method used a quasi experimental with consequtive sampling. This study included 30 patients in the gabapentin group and 26 patients in the amitriptyline group, and each group was evaluated for 1 month. Effectiveness was assessed using Visual Analogue Scale (VAS) every 2 weeks then analized by Mann Whitney test. The results showed that the use of gabapentin and amitriptilin in 4 weeks showed the decrease of pain score measured by visual analog scale $3.70 \pm 0.349$ and $3.500 \pm 0.34$ although there was no statistical difference $(p$ value $=0.704)$. To sum up, effectiveness of gabapentin and amitriptyline in the treatment of neuropathic pain did not have statistical difference.
\end{abstract}

Copyright (C) 2015 Institute of Advanced Engineering and Science. All rights reserved.

\section{Corresponding Author:}

Indriastuti Cahyaningsih,

Departement of Pharmacology and Clinical Pharmacy,

Universitas Muhammadiyah Yogyakarta,

Lingkar Barat, Kasihan, Tamantirto, Bantul.

Email: ndree_chy@yahoo.com, indriastuti.c@umy.ac.id

\section{INTRODUCTION}

There are two kinds of pain namely nosiseptic and neurophatic [1]. Neurophatic is a sensoric and emotional experience that is unpleasant and has significant influence toward a person's living quality [2]. Neurophatic pain has similar characteristic to the other cronical pains which influence significantly toward psychological, social function, and the other health aspects correlated to living quality of the people [3].

Neurophatic pain usually has not good response toward analgesic standard by World Health Organization (WHO), like non-steroid anti-inflamation medicine (NSAID) and opioid [4]. NSAID and asetaminofen are not effective toward neurophatic pain [1].

Antidepressant and antiepilepcy medicine become the first line of the medicine to overcome neurophatic pain [5]. Antidepressant has been proven to bring benefit in diabetes neurophatic, with the best effect can be reached by tricyclic antidepressant (TCA) [6]. Amitriptilin becomes one main choice for neurophatic pain from the group of tricyclic antidepressant [2]. Antiepilepcy medicine has shown its efficacy toward some types of neurophatic pain. Gabapentin has been approved by Food and Drug Administration (FDA) as an additional theraphy for partial epilepcy and management postherpetic neuralgia [7].

Gabapentin is included in the list of medicine plavon price (Daftar Plavon Harga Obat-DPHO) of health insurance in 2013 for the diagnose of postherphetic neuralgia (PHN) [8]. It is based on various evidences and researches which support gabapentin as a theraphy choice in PHN. Meanwhile, amitriptilin can 
generally be included in DPHO as one of the theraphies for some related diseases. By considering that there is not enough literature proving the effectivity of gabapentin as HNP theraphy, gabapentin as HNP theraphy has not been included in the plavon of health insurance DPHO.

Pheriphenal neurophaty pain is one of the causes of neurophaty pain [2]. Herniated nucleus pulposus (HNP) or known by slipped neuron disease is one kind of pheriphenal neurophaty pain. Most of the researches nowadays only focus on postherpetic neuralgia or diabetic peripheral neuropathy, but in this study the researcher focuses on patients with neurophaty pain having lesion or other diseases as painful cause including herniated nucleus pulposus.

\section{RESEARCH METHOD}

\subsection{Materials}

Tools and materials needed for this study were informed consents used to ask patients' willingness to be the subjects of the study. Besides, the researcher also used questioners to examine demographic data of the patients as well as to measure the effectivity between gabapentin and amitriptilin with Visual Analog Scale (VAS).

Visual Analog Scale is a measurement scale that is often used to measure pain intencity in the clinical test [9]. The score of VAS $0-<4$ can be categorized as light pain, $4-<7$ is medium pain, and $7-10$ is heavy pain [10]. The study used VAS as a scale measurement for pain intencity herniated nucleus pulposus patients with the measurement interval 2 weeks with monitoring time 1 month, so there would be available data for pain score with VAS scale in week 0 , week 2 and week 4.

\subsection{Research Process}

The research was conducted by measuring the effectivity gabapentin with the dose $100 \mathrm{mg} 2$ times a day or amitriptilin $12.5 \mathrm{mg}$ once in a day. Effectivity monitoring was done every one time in two weeks during 1 month treatment by regarding the score of VAS. This study was conducted in Jogja Hospital. Every patient was given one of the drugs (gabapentin or amitriptyline) and given a referral to physiotherapy. Physiotherapy was done 3 times a week for 2 weeks followed by twice a week for the next 2 weeks. In addition the patients were also asked to use the corset that had been provided. Patients not allowed to use the pain medication during the study. It aims to give the standart therapy for HNP and give equal treatment to all patient. The data was processed and analyzed by using Mann Whitney test to compare the effectivity from gabapentin and amitriptilin. On the other hand, descriptive analysis was used to describe socio-demographic factor, pain characteristic from the patients.

\section{RESULTS AND DISCUSSION}

\subsection{Respondents' Characteristic}

Complete data that could be analyzed were 56 respondents, in which 30 respondents were from the group taking gabapentin, and 26 respondents were from the group taking amitriptilin. Respondents' description can be seen from 4 characteristics such as age, gender, education background, and occupation. The data above can be explained in Table 1 .

Table 1 shows that the respondents were grouped into several categories such as age, gender, education background, and occupation. Based on statistical analysis using chi square test got the result respectively $0.556 ; 0.920 ; 0.601 ; 0.167$. It shows that there was no significant difference in every characteritis of the research subject, so it could be concluded that the subjects of the research were homogenous.

Based on the interview, responden experienced very disturbing pain in several days before having consultation to the hospital. Most of the patients said that they had pain before because of one thing such as lifting heavy load, falling down, or activities with high intencity. Here they are pain characteristic of the patients that is shown in Table 2 .

Table 2 shows that the main respondents' pain characteristics were to beat feeling that could be felt by 39 respondents $(69.64 \%)$. Sharp pain was felt by 33 respondents $(58.93 \%)$, burnt feeling could be felt by 20 respondents $(35.71 \%)$, and cramp could be felt by 21 respondents $(37.50 \%)$, while biting feeling could be felt by 18 respondents (32.14\%). HNP is one kind of neurotropic pain. The distinctive characteristic from neurotropic pain was sensations like being bitten, getting electrical shock, burnt, stiff, and numb. Patients usually felt the symtoms of allodynia (pain that is caused by the stimulus that does not cause any pain like touching) and hyperalgesia (increase respons toward stimulus that is usually hurt) [2]. 
Table 1. Demographic Characteristic of the Research Subjects

\begin{tabular}{|c|c|c|c|c|c|c|c|}
\hline \multirow{2}{*}{\multicolumn{2}{|c|}{ Respondents' Characteristic }} & \multicolumn{2}{|c|}{ Gabapentin } & \multicolumn{2}{|c|}{ Amitriptilin } & \multicolumn{2}{|c|}{ Respondent Total } \\
\hline & & Amount & Percentage (\%) & Amount & Percentage (\%) & Amount & Percentage (\%) \\
\hline \multirow[t]{7}{*}{ Age } & 21-30 year old & - & - & 1 & 3.85 & 1 & 1.79 \\
\hline & $31-40$ year old & - & - & 1 & 3.85 & 1 & 1.79 \\
\hline & $41-50$ year old & 4 & 13.33 & 4 & 15.38 & 8 & 14.29 \\
\hline & $51-60$ year old & 10 & 33.33 & 11 & 42.31 & 21 & 37.50 \\
\hline & $61-70$ year old & 11 & 36.67 & 7 & 26.92 & 18 & 32.14 \\
\hline & $71-80$ year old & 5 & 16.67 & 2 & 7.69 & 7 & 12.50 \\
\hline & Total & 30 & 100.00 & 26 & 100.00 & 56 & 100.00 \\
\hline \multirow[t]{3}{*}{ Gender } & Male & 10 & 33.33 & 9 & 34.62 & 29 & 51.79 \\
\hline & Female & 20 & 66.67 & 17 & 65.38 & 27 & 48.21 \\
\hline & Total & 30 & 100.00 & 26 & 100.00 & 56 & 100.00 \\
\hline Education & No School & - & - & 1 & 3.85 & 1 & 1.79 \\
\hline \multirow[t]{5}{*}{ Background } & SD & 4 & 13.33 & 6 & 23.08 & 10 & 17.86 \\
\hline & SMP & 6 & 20.00 & 5 & 19.23 & 11 & 19.64 \\
\hline & SMU & 9 & 30.00 & 8 & 30.77 & 17 & 30.36 \\
\hline & University & 11 & 36.67 & 6 & 23.08 & 17 & 30.36 \\
\hline & Total & 30 & 100.00 & 26 & 100.00 & 56 & 100.00 \\
\hline \multirow[t]{8}{*}{ Occupation } & Unemploymnt & - & - & 1 & 3.85 & 1 & 1.79 \\
\hline & Civil Servant & 4 & 13.33 & 4 & 15.38 & 8 & 14.29 \\
\hline & Private Sector & 1 & 3.33 & 3 & 11.54 & 4 & 7.14 \\
\hline & Enterpreneur & 8 & 26.67 & 1 & 385 & 9 & 16.07 \\
\hline & House Wife & 7 & 23.33 & 11 & 42.31 & 18 & 32.14 \\
\hline & Labour & 2 & 6.67 & 2 & 7.69 & 4 & 7.14 \\
\hline & Retired & 8 & 26.67 & 4 & 15.38 & 12 & 21.43 \\
\hline & Total & 30 & 100.00 & 26 & 100.00 & 56 & 100.00 \\
\hline
\end{tabular}

Table 2. The Characteristic of Respondents' Pain

\begin{tabular}{lcc}
\hline \multicolumn{1}{c}{ Pain Characteristics } & The Number of Respondents & Percentage (\%) \\
\hline Beating & 39 & 69.64 \\
Sharp & 33 & 58.93 \\
Burnt & 20 & 35.71 \\
Cramp & 21 & 37.50 \\
Biting & 18 & 32.14 \\
\hline
\end{tabular}

Pain location felt by the patients was also various; they were in the back bone, leg, and tigh. Pain location of the respondents is showed in Table 3. Table 3 shows that 34 respondents $(60.71 \%)$ experienced the pain in the back bone and leg. Respondents who experienced the pain only in the back were 13 respondents $(23.21 \%)$. There were 8 respondents $(14.29 \%)$ who experienced the pain only in the leg, and 1 respondent $(1.79 \%)$ experienced the pain in the back bone and tigh.

Table 3. Respondents' Pain Location

\begin{tabular}{lcc}
\hline \multicolumn{1}{c}{ Pain Location } & The Number of the Respondents & Percentage (\%) \\
\hline Back bone and leg & 34 & 60.71 \\
Back bone & 13 & 23.21 \\
Leg & 8 & 14.29 \\
Back bone until tigh & 1 & 1.79 \\
Total & 56 & 100.00 \\
\hline
\end{tabular}

The pain of nosiseptic experienced by the patients could easily explain the pain location exactly, but the patients with neurotropic pain sometimes get difficulties to mention the location of the pain exactly because neurotropic pain is sometimes wider [1]. HNP pain with the source of the back bone often spreads to the leg or to the reproduction organ because of the existence of cauda equine, a group of neuron connecting and providing the communication with low extremity and duodenum control, urether, and sexual function [11]. In an extreme condition, discus experiencing herniation is able to press the edge of the neuron in cauda equine which causes cauda equine syndrome causing bilateral pain in the leg, both legs paralyze, and disability to hold the pee [12].

\subsection{The Analisys of Visual Analog Scale (VAS)}

Initial measurement to the score of pain intencity using VAS can be done when the patients fulfill incoming inclusion criteria to receive the medicine and conducting interview. The patients were asked to assess their pain intencity with VAS scale. The result of the research shows that the initial measurement

The Comparison of Gabapentin and Amitriptilin Effectivity as Pain Therapy .... (Indriastuti Cahyaningsih) 
(week 0) patients in the group of gabapentin 93\% had heavy pain and $7 \%$ medium pain, while in the group of amitriptilin $80.7 \%$ had heavy pain and $19.3 \%$ medium pain. The result of the research was similar to a research conducted by Ohtori et. al. (2013) mentioning that the patients with herniated nucleus pulposus diagnose usually had pain intencity measured with VAS scale around 5-9 [13].

The patients given gabapentin theraphy in this research were 30 . Regiment of the dose based on guideline NICE (2010) mentions that for the theraphy of neurophaty pain, the dose of gabapentin adviced is 100-300 $\mathrm{mg}$ before sleeping or 100-300 $\mathrm{mg}$ in a day [2]. However, the dose used in this research was $100 \mathrm{mg}$ $2 \mathrm{x}$ in a day. It was done because in the previous study with the dose of $300 \mathrm{mg}$ in a day, most of the patients complained of its side effect that made them feeling weak and disturbed, so they were not able to tolerate that condition.

The patients who got amitriptilin theraphy were 26. Amitriptilin dose given was $12.5 \mathrm{mg}$ in the evening. The regiment of this dose is based on NICE (2010) mentioning that the dose of amitriptilin for the theraphy of neuropathic pain was $10-75 \mathrm{mg}$ once a day [2].

Based on the normality test, it got the information that the data from the value of visual analog scale (VAS) was completely distributed with $\mathrm{p}$ value $>0.05$ both for gabapentin group and for amitriptilin group. It indicates that it can be analyzed by using paired sample $t$ test. The result of this test is presented in Table 4 .

Table 4. The Comparison of Score Decrease of VAS in Gabapentin and Amitriptilin Group

\begin{tabular}{ccccc}
\hline VAS Measurement & Treatment Group & $\mathbf{N}$ & Mean Score of Declining VAS & p value \\
\hline \multirow{2}{*}{ Week 0 to week 2} & gabapentin & 30 & $1.967 \pm 0.211$ & 0.340 \\
& amitriptilin & 26 & $1.731 \pm 0.219$ & \\
Week 0 to week 4 & gabapentin & 30 & $3.700 \pm 0.349$ & 0.704 \\
& amitriptilin & 26 & $3.500 \pm 0.343$ & \\
\hline
\end{tabular}

Based on Table 4 can be known that the result of VAS score decrease in week 2 and week 4 did not have significant different of the effectivity of gabapentin group and amitriptilin group. It can be shown from $\mathrm{p}$ value which was more than 0.05 .

The result of the research is similar to a research conducted by Morello dkk (1999) showing that there was no significant difference between gabapentin and amitriptilin group in its effectivity for painful with diabetes mellitus (PDN) [6]. A research done by Dallocchio dkk (2000) showed higher pain decrease than the patients with gabapentin treatment, but it was not different statistically [14]. Another research conducted by Vega (2010) explains the comparison of amitriptilin effectivity and pregabalin effectivity in the theraphy of painful diabetic neuropathy [15]. Pregabalin is an anticonvulsant which also becomes one of the first line theraphies for neurophatic pain which has action mechanism like gabapentin [2]. The result of the research shows that there was no significant difference in decreasing the pain.

The result of this research also shows that both gabapentin group and amitriptilin group show pain decrease if it was compared before and after the theraphy. Statistically it shows significant difference with $p$ value $0.000(\mathrm{p}<0.05)$. This result indicates that amitriptilin and gabapentin are effective as pain killer theraphy in herniated nucleus pulposus. The result of the analysis is presented in Table 5.

Table 5. Comparison Analysis Result of VAS Score by Giving Gabapentin and Amiriptilin

\begin{tabular}{lcc}
\hline \multicolumn{1}{c}{ Information } & Gabapentin & Amitriptilin \\
\hline Mean \pm SE week 0 & $8.733 \pm 0,262$ & $8.346 \pm 0.337$ \\
Mean \pm SE week 4 & $5.033 \pm 0,360$ & $4.846 \pm 0.406$ \\
$\mathrm{p}$ value & 0.000 & 0.000 \\
\hline
\end{tabular}

This result is similar to some researches related to both gabapentin effectivity and amitriptilin eefctivity to neurophatic pain such as Backonja et. al. (1998) conducting a research to the patients with Painful Neuropathy in Patients with Diabetes Mellitus diagnose [16]. VAS value from the patients getting gabapentin theraphy had decrease from 6.4 becoming 3.8 after 8 weks, compared to placebo group from 6.5 becoming 5.1 with $\mathrm{p}$ value $<0.001$.

\subsection{Side Effect}

Side effect becomes one of the parameters which need to be considered in choosing a particular theraphy. Side effect does not always appear in every patient, but it should become an alert so that the patients can anticipate it. The existence of its efefctivity evidence of the medicine for the theraphy of 
neurophatic pain is significantly needed to health staffs to determine the most effective medicine in reducing pain and having minimal adverse effect. Ideally, the evidence of choosing medicine in a particular algorithm is based on its direct comparison one medicine with the others, both its efficacy and its side effect [17].

In this research, most of the patients did not experience significant side effect. Only several people got its side effect, but it was still able to be tolerated, so they were atill able to follow thetheraphy session. However, there were some patients dropping out because they could not tolerate the incoming side effect. It happened from both gabapentin group and amitriptilin group. One of the patients complained disturbing fatigue after consuming amitriptilin, besides there was sedation effect that disturbed the patients' daily activities, so they could not continue to participate in the research. In gabapentin group, there were some patients complaining to have stiff feeling after consuming gabapentin, so the patients determined to drop out. The side effect of the medicine both in gabapentin group and in amitriptilin group is presented in Table 6 .

Table 6. Side Effect in the Patients Having Theraphy with Gabapentin and Amitriptilin

\begin{tabular}{lcc}
\hline \multicolumn{1}{c}{ Side Effect } & Gabapentin & Amitriptilin \\
\hline Sedative & & 9 \\
Dry mouth & 1 & 1 \\
Neusea & 3 & 1 \\
Headache & & 1 \\
Tired & 1 & 12 \\
Total & 5 & \\
\hline
\end{tabular}

Based on Table 6, it is known that the stage of side effect coming to the group of amitriptilin was sedation with $30 \%$, dry mouth, headache, and tiredness respectively $3.3 \%$ from 30 patients. While 31 patients got gabapentin theraphy $3.2 \%$ reported dry mouth, $3.2 \%$ tiredness $9.7 \%$ feeling nauseated. This side effect is similar to the previous researches related to the use of gabapentin and amitriptilin.

Side effect of amitriptilin was mostly reported by some researches such as a research conducted by Vega (2010) mentioning that the patients with painful diabetic neuropathy got some side effects like sleepiness $43 \%$ for amitriptilin and $20 \%$ to the patients with pregabalin. A research result by Kaur, et. al. (2011) also explains that the use of amitriptilin shows the most often side effect like dry mouth (28.8\%) with p value $<0,001$ and sleepiness $18.9 \%$ from 111 occurences, the side effect reported was 58 patients taking part to the research [18]. Adverse effect from amitriptilin can appear toward cardiovascular system like postural hypotension, takikardi; central neuron system like anxiety, headache, extrapirimidal symptoms, insomnia, sedation and skin effect like photosensitive, alergi, urtikaria, digestion system like constipation, increasing weight and low vision, midriasis [19].

A research conducted by Rintala et al (2007) compared the use of amitritptilin and gabapentin as pain theraphy in spinal cord injury, the patients reported that the side effect of using amitriptilin was dry mouth (63.8\%), sleepiness (27.1\%), and constipation (29.2\%), tiredness (20.5\%) [20]. A similar theory was also reported by the patients who got gabapentin theraphy with the same occurrence stage.

Adverse effect from gabapentin can appear such as sedative, dry mouth, headache, postural hipotension, ataxia, constipation, letargi, edema, pruritis, incomfortable feeling, diarhea, nausea, unclear vision, and the others [6]. According to Morello, it is also explained that the use of amitriptilin in neurophaty pain theraphy, the side effect that is mostly experienced by the patients are sedative and dry mouth that can be worse from time to time. Meanwhile, in the use of gabapentin the side effect reported was sedative and headache. The other side effects experienced by the patients are postural hypotension, weight increase, ataxia and letargi although it appears in low prevalence.

Based on the discussion above, it can be concluded that the side effect of gabapentin and amitriptilin is basically similar, but in this research sedative side effect mostly could be found by the patients getting amitriptilin theraphy, while gabapentin did not report more side effect reported by the respondents. It is possible because the effect of antidepressant from the amitriptilin was bigger, so it had more effect to calm down or sedative. The side effect cannot be separated from the medicine and individual condition of the patients. The treatment can decrease pain intencity of the patients, and it is closely correlated to the increase of living quality, but it did not decrease its side effect [21].

\section{CONCLUSION}

The use of gabapentin and amitriptilin in 4 weeks showed the decrease of pain score measured by visual analog scale $3.70 \pm 0.349$ and $3.500 \pm 0.343$ with $p$ value $>0.05$ which means that it was not significantly different, Reported side effect from the use of gabapentin was $3.2 \%$ feeling dry mouth, $9.7 \%$

The Comparison of Gabapentin and Amitriptilin Effectivity as Pain Therapy .... (Indriastuti Cahyaningsih) 
feeling nausea and 3.2\% feeling tiredness; while for the use of amitriptilin was sedative $30 \%$, dry mouth, headache and tiredness respectively $3.3 \%$.

\section{REFERENCES}

[1] Pappagallo, M., "Newer Antiepileptic Drugs: Possible Uses in The Treatment of Neuropathic Pain and Migraine", Clinical Therapeutics, vol. 25, pp. 2506-2538, 2003.

[2] NICE, "Neuropathic Pain: The Pharmacological Management of Neuropathic Pain in Adults in Non-Specialist Settings", National Insititute for Health and Clinical Excllence, London, 2010.

[3] Serpell, M. G., "Gabapentin in Neuropathic Pain Syndromes: A Randomised, Double-Blind, Placebo-Contrlled Trial", Pain, vol. 99, pp. 557-566, 2002.

[4] Karlsten, R., Gordh, T., "How Do Drugs Relieve Neurogenic Pain?”, Drugs Aging, vol. 11, pp. 398-412, 1997.

[5] Gordh, T. E., Stubhaug, A., Jensen, T. S., Arnér, S., Biber, B., Boivie, J., Mannheimer, C., Kalliomäki, J., Kalso, E., "Gabapentin in Traumatic Nerve Injury Pain: A Randomised, Double-Blind, Placebo-Controlled, Cross-Over, Multi-Center Study”, Pain, vol. 138, pp. 255-266, 2008.

[6] Morello, C. M.,Susan, G. L., Carol, P. S., David, F. M., Gregory, A. S., "Randomized Double-blind Study Comparing the Efficacy of Gabapentin with Amitriptyline on Diabetic Peripheral Neuropathy Pain", Arch Intern Med, vol. 159, pp. 1931-1937, 1999.

[7] VHA, "Guidance on the Use 2004. http://www.pbm.va.gov/Clinical\%20Guidance/Clinical\%20Recommendations/Gabapentin,\%20Clinical\%20Recom mendations.pdf, accessed on 14 February 2013.

[8] Askes, "The list of Medicine Plavon Price", PT Askes Tbk, Jakarta, 2013.

[9] Jensen, M. P., Chen, C., Brugger, A. M., "Interpretation of Visual Analog Scale Ratings and Change Scores: A Reanalysis of Two Clinical Trials of Postoperative Pain”, The Journal of Pain, vol/issue: 4 (7), pp. 407-414, 2003.

[10] Iqbal, K. M., Rambe, A. S., Sjahrir, H., "The Comparison of Visual Analog Scale Score With Verbal Scale Degrees Head Pain in Patients Primer In Adam Malik Hospital”, Nusantara Medical Magazine, vol/issue: 38(4), pp. 279$285,2009$.

[11] AANN, "Lumbar Spine Surgery: A Guide to Preoperative and Postopreative Patient Care, Medtronic's Spinal ad Biologicals", America, 2006.

[12] Perry, M., "HNP Causes-Common Reasons for a Herniated Nucleus Pulposus", 2012. http://www.laserspineinstitute.com/back_problems/hnp/causes/, accessed on 2 September 2013.

[13] Ohtori, S., Inoue, G., Eguchi, Y., Orita, S., Takaso, M., Ochial, N., Kishida, S., Kuniyoshi, K., Aoki, Y., Nakamura, J., Ishikawa, T., Arai, G., Miyagi, M., Kamoda, H., Suzuki, M., Sakuma, Y., Oikawa, Y., Kubota, G., Sainoh, T., Toyone, T., Yamauchi, K., Kotani, T., Akazawa, T., Minami, S., Takahashi, K., "Tumor Necrosis Factor $\alpha-$ Immunoreactive Cells in Nucleus Pulposus in Adolescent Patients With Lumbar Disc Herniation", Spine, vol/issue: 38(6), pp. 459-462, 2013.

[14] Dallocchio C., Buffa C., Mazzarello P., Chiroli S., "Gabapentin vs. amitriptyline in painful diabetic neuropathy: An open-label pilot study", J Pain Symptom Manage, vol. 20, pp. 280-28, 2000.

[15] Vega C. P., "Best Evidence Review: Amitriptyline vs Pregabalin for Painful Diabetic Neuropathy- A Rare Head to Head Comparasion", Pubmed, 2010.

[16] Backonja, M., Beydoun, A., Edwards, K. R., "Gabapentin for the Symptomatic Treatment of Painful Neuropathy in Patients with Diabetes Mellitus: A Randomized Controlled Trial”, JAMA, vol. 280, pp. 1831-1836, 1998.

[17] Finnerup, N. B., Otto, M., McQuay, H. J., Jensen, T. S., Sindrup, S. H., "Algorithm for Neuropathic Pain Treatment: An Evidence Based Proposal”, Pain, vol. 118, pp. 289-305, 2005.

[18] Kaur, H., Hota, D., Bhansali, A., Dutta, P., Bansal, D., Chakrabarti, A., "A Comparative Evaluation of Amitriptyline and Duloxetine in Painful Diabetic Neuropathy”, Diabetes Care, vol 34, pp. 818-822, 2011.

[19] Lacy, C. F., Armstrong, L. L., Goldman, M. P., Lance, L. L., "Drug Information Handbook", Lexi-Comp Inc, Ohio, 2002.

[20] Rintala, D. H., Holmes, S. A., Courtade, D., Fiess, R. N., Tastard, L. V., Loubser, P. G., "Comparison of The Effectiveness of Amitriptyline and Gabapentin on Chronic Neuropathic Pain in Persons With Spinal Cord Injury", Arch. Phys. Med. Rehabil, vol. 88, pp. 1547-1558, 2007.

[21] O'Connor A. B., "Neuropathic pain: Quality of Life Impact, Cost and Cost Effectiveness of Therapy", Pharmacoeconomics, vol/issue: 27(2), pp. 95-112, 2009. 


\section{BIOGRAPHIES OF AUTHORS}

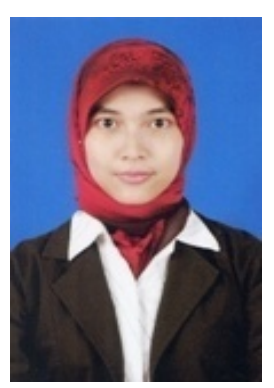

Indriastuti Cahyaningsih is a lecturer of pharmacology and clinical pharmacy science at School of pharmacy, Universitas Muhammadiyah Yogyakarta. She was born on May 26 $6^{\text {th }}, 1985$ in Yogyakarta. She got graduation, pharmacy by training, and master of science at Gadjah Mada University, Yogyakarta, Indonesia.

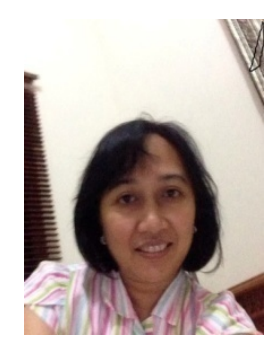

Rina Handayani is a one of lecturer at Gadjah Mada University. She is a doctor. She has passion in pharmacology science. There are several research that she had been produced.

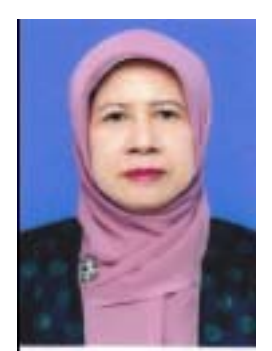

Setyaningsih is a neurologist at Jogja hospital. She was born on July $1^{\text {th }}, 1958$ in Metro Lampung, Sumatera. She got graduation on 1999 at Gadjah Mada University, Yogyakarta, Indonesia. Her hobby is reading and shopping. 